Nat Rev Clin Oncol. ; 8(8): 479-491. doi:10.1038/nrclinonc.2011.63.

\title{
Treatment of multiple myeloma
}

\author{
S. Vincent Rajkumar \\ Division of Hematology, Mayo Clinic College of Medicine, 200 First Street SW, Rochester, \\ MN355905, USA
}

S. Vincent Rajkumar: rajkumar.vincent@mayo.edu

\section{Abstract}

The treatment of multiple myeloma has changed dramatically in the past decade. The increase in the number of active agents has generated numerous possible drug combinations that can be used in the first-line and relapsed settings. As a result, there is considerable confusion about the choice of regimens for initial therapy, role of transplantation in the era of new drugs, end points for therapy, and the role of maintenance therapy. A hotly debated area is whether treatment approaches should achieve cure or disease control, which impacts greatly on the treatment strategy employed. This article provides an update on the treatment of multiple myeloma, with a focus on recent advances, newly diagnosed disease, role of transplantation and maintenance therapy. A synthesized approach to the treatment of myeloma is presented, along with a discussion of key paradigms that need to be challenged.

\section{Introduction}

Multiple myeloma is a malignant monoclonal plasma cell disorder characterized by osteolytic bone lesions, anemia, hypercalcemia, and renal failure. ${ }^{1,2}$ It has an age-adjusted incidence of approximately four per 100,000 and accounts for 10\% of all hematologic malignancies. ${ }^{3}$ The median age at diagnosis is approximately 65 years, and the disease is more common in black people compared with white people. ${ }^{4}$ Unlike most other malignancies, the diagnosis of multiple myeloma is not histopathologic, but requires specific clinical features; multiple myeloma represents a 'clinicopathologic' entity. Diagnosis involves evidence of a clonal plasma cell disorder (that is, $10 \%$ or more plasma cells on bone marrow examination or biopsy-proven plasmacytoma) and evidence of end-organ damage (hypercalcemia, renal insufficiency, anemia, or bone lesions) that can be attributed to the plasma cell disorder. ${ }^{5}$

Although multiple myeloma is considered to be a single disease, it consists of at least six non-overlapping cytogenetic subtypes (Table 1). It is likely that with improved understanding of disease pathogenesis, each cytogenetic category will be considered a distinct entity for purposes of diagnosis and therapy. The cytogenetic subtypes are evident early in the course of the disease, and might be a precursor event associated with the transformation of normal plasma cells to the clonal premalignant stage-referred to as monoclonal gammopathy of undetermined significance (MGUS). ${ }^{6}$ MGUS is present in 3$4 \%$ of the general population, but progression to multiple myeloma is infrequent, occurring at a rate of $1 \%$ per year. ${ }^{7,8}$ Progression of MGUS is associated with the development of osteolytic bone lesions in most patients. The pathogenesis of bone disease involves an

(C) 2011 Macmillan Publishers Limited. All rights reserved

Competing interests

The author declares no competing interests. 
increase in RANKL (receptor activator of nuclear factor KB ligand) accompanied by a reduction in the level of its decoy receptor, osteoprotegerin, resulting in sustained osteoclast activation. Simultaneously, overexpression of dickkopf 1 inhibits osteoblast differentiation resulting in suppression of healing and new bone formation. ${ }^{9}$

Multiple myeloma has been a frustrating disease to treat. The median overall survival was approximately 3 years until the late 1990s. Since then dramatic outcome improvements have occurred owing to the new active agents thalidomide, ${ }^{10}$ bortezomib, ${ }^{11}$ and lenalidomide, ${ }^{12,13}$ autologous stem-cell transplantation (ASCT) and improvements in supportive care; the 3-year survival rates have exceeded $75-80 \% .{ }^{14,15}$ The median survival is in excess of 5 years.

The improved treatment options have brought much hope and enthusiasm, but new challenges have developed as a result of these advances. There are a plethora of regimens that can be used resulting in considerable heterogeneity in how patients are treated across institutions, countries, and continents. The role of ASCT, end points of therapy, and value of risk stratification are all important areas of debate and disagreement. There is also a major debate on the overall goal of treatment in light of the various treatment options: cure versus control. ${ }^{16}$

This Review presents a summary of the current data on the treatment of multiple myeloma, provides recommendations for therapy based on the available evidence, addresses the major areas of controversy, and gives directions on ongoing and future areas of research. Recent randomized trials on the treatment of multiple myeloma that significantly affect the overall therapeutic strategy are highlighted. Smaller phase I and II trials and observational studies are included based on historical value, novelty or clinical importance.

\section{Risk-stratification}

Survival for patients with multiple myeloma depends on certain basic variables including, age, performance status, renal function, and disease stage. There are two methods of staging: the Durie-Salmon Stage (DSS), ${ }^{17}$ and the International Staging System (ISS). ${ }^{18}$ Both staging systems have limitations. The DSS is limited by complexity and subjectivity, while the ISS is neither specific for multiple myeloma nor related to disease burden. Nevertheless, these basic variables are useful for estimating outcomes and comparing patient populations enrolled in clinical trials. Overall outcome for an individual patient according to age, stage and performance status is refined using a risk-stratification model that incorporates the underlying cytogenetic type (Table 2) ${ }^{19}$ Such risk stratification requires molecular cytogenetic studies to detect specific abnormalities, such as the translocations $t(11 ; 14)$, $\mathrm{t}(4 ; 14), \mathrm{t}(14 ; 16), \mathrm{t}(6 ; 14), \mathrm{t}(14 ; 20)$, hyperdiploidy, and deletion $17 \mathrm{p} .{ }^{20}$ Gene-expression profiling can also be used to generate specific signatures associated with adverse prognosis. ${ }^{21}$ The risk stratification suggested in Table 2 segregates patients with standard risk who can expect median survival of $\searrow 6-7$ years, from those with high-risk disease who have a median expected survival of approximately 3 years with current therapy. Patients with intermediate risk may have similar survival rates to patients with standard risk when treated at an early stage with bortezomib in combination with ASCT.

\section{Treatment of smoldering myeloma}

Virtually all multiple myeloma patients have a prolonged asymptomatic phase that can be detected many years before diagnosis of multiple myeloma. ${ }^{6}$ This asymptomatic phase is clinically recognized as MGUS (a premalignancy) ${ }^{7,8}$ or a more advanced indeterminate stage termed smoldering multiple myeloma (SMM) ${ }^{22}$ In a study of 276 patients with SMM, the risk of progression to multiple myeloma in the first 5 years following diagnosis was $10 \%$ 
per year-as would be expected in patients with early-stage multiple myeloma. ${ }^{22}$ In the next 5 years the risk of progression decreased to $3 \%$ per year, and after 10 years of follow up the risk of progression was the same as MGUS. As the risk decreases dramatically over time, we can conclude that SMM is not a unique biologic entity, but a clinical condition that is likely comprised of approximately $50 \%$ of patients with MGUS (premalignant clonal expansion) and approximately $50 \%$ of patients who have multiple myeloma (malignant disease) who have not yet developed serious clinically recognizable end-organ damage. ${ }^{23}$

Histopathologic and other laboratory methods cannot differentiate between MGUS and multiple myeloma since there is no clear marker that can distinguish a clonal premalignant plasma cell from a clonal malignant multiple myeloma cell. The diagnosis of multiple myeloma depends on overt clinical manifestations of serious end-organ damage. Without manifestations such as bone destruction or fractures, or renal failure it is not possible to distinguish patients with SMM who have malignant transformation destined to progress in the next 1-2 years from those who have MGUS who may remain stable for 5-10 years or longer. Owing to this uncertainty, all patients with SMM are currently observed without any treatment until major end-organ damage occurs.

Delaying therapy until end-organ damage was thought to be reasonable because active drugs such as melphalan and corticosteroids have considerable toxicity. Two trials conducted before the arrival of new agents concluded that there was no overall survival benefit when alkylating agents were given early or delayed for SMM; however, these trials were significantly underpowered. ${ }^{24,25}$ This situation has been perpetuated because of our inability to discriminate multiple myeloma from MGUS without the diagnostic aid provided by the presence or absence of end-organ damage. This status quo is difficult to accept when we have several agents that induce extraordinary levels of complete response (CR). The overall treatment paradigm of waiting until development of end-organ disease needs to be reexamined.

One way to overcome the status quo is to identify specific biomarkers (or set of biomarkers) present at baseline that will accurately identify patients with SMM who have undergone malignant transformation-defined as a $90 \%$ or higher probability of progression to symptomatic multiple myeloma within 2 years (false-positive rate $₫ 0 \%$ ). Such a study has been undertaken by the Southwest Oncology Group (SWOG S0120) using gene-expression profiling to assess patients with SMM. At present, the most promising biomarkers include plasma cell immunophenotype, serum free light chain ratio, circulating plasma cells, plasma cell proliferation rate, and presence or absence of $R A S$ mutations or $M Y C$ abnormalities. A second approach is to demonstrate clinical benefit in randomized trials. Initial studies with lenalidomide plus dexamethasone are promising, ${ }^{26}$ and other randomized trials are underway. Until one of these two strategies is established, patients with SMM should not receive therapy, but are candidates for clinical trials investigating experimental approaches such as lenalidomide, or other agents with low toxicity.

\section{Treatment of newly diagnosed myeloma}

Initial therapy for multiple myeloma depends to a certain extent on eligibility for ASCT. Patients who are considered potential candidates for ASCT are usually treated with two to four cycles of non-melphalan containing induction therapy before stem-cell harvest. ${ }^{27}$ After stem-cell harvest, most patients proceed to ASCT (early ASCT approach), while some resume induction therapy and reserve ASCT for relapse (delayed ASCT approach). Eligibility for stem-cell transplantation is determined by age, performance status, and comorbidities. In the USA, the upper age limit for ASCT is approximately 75 years. In most European countries, patients 65 years and older are not considered candidates for ASCT. In 
general, prolonged melphalan-based therapy should not be used for patients who are considered eligible for ASCT because it can interfere with adequate stem-cell mobilization.

\section{Non-melphalan containing therapy regimens}

Non-melphalan containing regimens were developed primarily for patients who are candidates for ASCT, but most newer regimens are well tolerated and are suitable for patients who are not candidates for ASCT. The most frequently used regimens for the treatment of newly diagnosed multiple myeloma (Tables 3 and 4) are thalidomide plus dexamethasone (TD), lenalidomide plus low-dose dexamethasone (Rd), bortezomib plus dexamethasone (VD), bortezomib, thalidomide, dexamethasone (VTD), bortezomib, lenalidomide, dexamethasone (VRd) and bortezomib, cyclophosphamide, dexamethasone (VCD).

Two-drug combinations-In newly diagnosed multiple myeloma, TD produced response rates of $65-75 \%$ in phase II trials. ${ }^{28-30}$ Two randomized trials found TD to be superior to dexamethasone alone, leading to the approval of the this drug combination. ${ }^{31,32}$ However, TD has fallen out of favor recently. First, the toxicity and early mortality rates with TD are unacceptably high. In the two randomized trials discussed, approximately $20 \%$ of patients developed deep vein thrombosis (DVT), and the early mortality rate was approximately $10 \% .{ }^{31,32}$ Second, in a phase III study overall survival with TD was inferior to melphalan and prednisone. ${ }^{33}$ Third, in a study of 411 newly diagnosed patients, lenalidomide plus dexamethasone was significantly superior to TD in terms of response rate, progression-free survival (PFS), and overall survival. ${ }^{34}$ Nevertheless, TD remains an option when lenalidomide or bortezomib are not available for initial therapy, with or without the addition of cyclophosphamide. ${ }^{35}$ Patients receiving TD or other thalidomide-based regimens require DVT prophylaxis with aspirin, low-molecular-weight heparin, or coumadin. ${ }^{36,37}$

Lenalidomide is a safer and more effective analog of thalidomide. ${ }^{12} \mathrm{~A}$ randomized trial showed that lenalidomide plus dexamethasone was superior to dexamethasone alone in newly diagnosed multiple myeloma. ${ }^{38}$ Superior overall survival with reduced toxic effects was demonstrated for Rd compared with lenalidomide plus high-dose dexamethasone. ${ }^{14}$ The respective 1 -year overall survival was $96 \%$ versus $87 \%$ and the early (4 month) mortality rate was $0.5 \%$ versus $5 \%$. Based on this trial, the use of high-dose dexamethasone is no longer recommended in newly diagnosed multiple myeloma. The toxicity of dexamethasone makes it difficult to incorporate into multiagent regimens. Most recent trials in newly diagnosed multiple myeloma now incorporate low-dose dexamethasone ( $40 \mathrm{mg}$ once a week or equivalent).

Rd may impair collection of peripheral blood stem cells for transplant in some patients when mobilized with granulocyte colony-stimulating factor (G-CSF) alone. ${ }^{39}$ Stem-cell mobilization in these patients is usually successful with a chemotherapy-containing mobilization regimen such as cyclophosphamide and G-CSF. Plerixafor, a CXCR4 inhibitor mobilizing agent usually allows adequate stem cell collection in the subset of patients who have difficulty mobilizing with G-CSF alone. All patients treated with Rd require antithrombosis prophylaxis with aspirin, low-molecular-weight heparin, or coumadin. ${ }^{36,37}$

In newly diagnosed multiple myeloma, treatment with VD results in response rates of approximately $70-90 \% .{ }^{40,41}$ Harousseau and colleagues compared VD with vincristine, adriamycin, dexamethasone (VAD) as pre-transplant induction therapy. ${ }^{42}$ Response rates before and after transplant were better with VD than VAD; the post-induction very good partial response (VGPR) was $38 \%$ versus $15 \%$. Corresponding post-transplant VGPR rates were $54 \%$ and $37 \%$. Disappointingly, this did not translate into major improvements in PFS 
or overall survival. The improvement in PFS was modest (36 months versus 30 months) and did not reach statistical significance. To date, no overall survival benefit is apparent.

$\mathrm{Rd}$ and VD have never been compared directly in a randomized trial. The major advantage of VD is the absence of increased risk of DVT, the lack of any adverse effect on stem-cell mobilization, and higher $\mathrm{CR}$ rates. The major drawback of VD is the risk of neurotoxicity early in the disease course, which can occur abruptly and can be very debilitating. However, the risk of neuropathy can be reduced dramatically by lowering the bortezomib dose to once a week without any significant loss of efficacy. ${ }^{43}$ As a result, once weekly bortezomib is preferred in most patients for initial therapy, unless there is a need for rapid disease control. ${ }^{44} \mathrm{VD}$ and similar bortezomib-based regimens are of particular value in patients presenting with acute renal failure, ${ }^{45}$ and in patients with high-risk multiple myeloma.

Three-drug combinations-Results with the three-drug combinations indicate better overall response rates, deeper and higher CR rates, and longer PFS compared with two-drug combinations ( $\mathrm{Rd}$ or $\mathrm{VD}$ ). However, it is not clear whether the incorporation of three active agents in those with newly diagnosed multiple myeloma results in prolongation of overall survival compared with a sequential approach. Also unknown is the effect on quality of life. Advocates of a curative approach argue in favor of triplet combinations since they have the promise of superior CR rates, while those in favor of a disease-control approach argue for a risk-adapted strategy where the intensity of initial therapy is adjusted based on the underlying molecular cytogenetic type of multiple myeloma. Numerous combinations have been developed, and the most commonly used regimens are discussed below.

Cavo et al. ${ }^{15}$ compared the pre-transplant induction therapy VTD with TD. VTD resulted in better response rates and PFS, but no overall survival benefit. Similarly, in another randomized trial, VTD resulted in better response rates compared with VD. ${ }^{46}$ VTD is particularly useful in the setting of acute renal failure since it acts rapidly and can be used without dose modification.

VRd produces high overall response and CR rates for treating newly diagnosed multiple myeloma ${ }^{47}$ In the USA, a SWOG randomized trial is currently comparing VRd with Rd. VRd has been adopted as the standard front-line regimen in an ongoing international study comparing early versus delayed transplantation. ${ }^{48} \mathrm{VCD}$ is another three-drug combination that has shown significant activity in newly diagnosed multiple myeloma, with results comparable to those seen with VTD and VRd. ${ }^{49}$ Preliminary results from a recent phase II randomized trial showed similar activity compared with VRd. ${ }^{50}$

Other regimens-TAD (thalidomide, doxorubicin, dexamethasone) and PAD (bortezomib, doxorubicin, dexamethasone) provide better response rates compared with the parent regimens TD and VD. ${ }^{51,52}$ Several other regimens have been tested in newly diagnosed patients, but randomized controlled trials have not shown a clear effect on longterm end points compared with the regimens discussed above. Multiagent combination chemotherapy, such as VDT-PACE (bortezomib, dexamethasone, thalidomide, cisplatin, doxorubicin, cyclophosphamide, and etoposide) may be an important option for patients with very aggressive disease such as plasma-cell leukemia or multiple extramedullary plasmacytomas. ${ }^{53}$ The Evolution trial combined bortezomib, dexamethasone, cyclophosphamide and lenalidomide (VDCR) in a four-drug combination, but responses were not superior to either VRd or VCD. ${ }^{54}$

\section{Melphalan-containing initial therapy regimens}

Melphalan-based regimens (Table 5) are typically reserved for patients who are not candidates for ASCT, and are usually used for 9-18 months. The use of melphalan- based 
therapy is decreasing because many of the non-melphalan-based regimens, especially Rd, VRd, and VCD are excellent options for non-transplant candidates aged 65-75 years. In patients over the age of 75 years, $R d$ is probably better tolerated than many of the melphalancontaining regimens discussed below. For example, in two recent studies, ${ }^{55,56}$ the 3-year overall survival rate with $\mathrm{Rd}$ was $70 \%$ in patients aged $\geq 70$ years, comparable to three-drug combinations such as melphalan, prednisone, thalidomide (MPT) or bortezomib, melphalan, prednisone (VMP). The results of a recently completed phase III trial assessing MPT versus Rd for 18 months versus Rd until progression might settle the question of whether melphalan-containing regimens can be retired from front-line use in the future.

Two-drug combinations-MP has been used in the treatment of multiple myeloma for over four decades. It acts slowly, and the appropriate dosage may be difficult to establish in some patients. The response rate is approximately $50 \%$, but less than $5 \%$ of patients achieve a CR. The median survival is approximately 3-4 years. A meta-analysis of 26 randomized trials found superior response rates but no survival benefit with combination chemotherapy regimens compared with MP before the arrival of thalidomide and bortezomib. ${ }^{57} \mathrm{MP}$ may still have a role in elderly patients who do not have access to Rd, and in whom therapy with MPT or VMP is not considered safe or feasible because of advanced age (>80 years) or significant comorbidities. ${ }^{57,58}$

The substitution of dexamethasone in place of prednisone (melphalan plus dexamethasone; MDex) improves response rate and the speed of response, but is more toxic and does not improve overall survival. ${ }^{59}$ In some countries, cyclophosphamide has been used in place of melphalan, either as cyclophosphamide plus prednisone or cyclophosphamide plus dexamethasone.

Three-drug combinations-Five randomized studies have shown that melphalan, prednisone, thalidomide (MPT) improves response rates compared with MP. ${ }^{60-64}$ Four of these trials have shown a significant prolongation of PFS with MPT, ${ }^{60-62,64}$ and an overall survival advantage. ${ }^{57-61}$ The trial by Facon et al..$^{60}$ that assessed MPT versus MP versus tandem ASCT with reduced-dose melphalan $\left(100 \mathrm{mg} / \mathrm{m}^{2}\right)$ was the first trial to show a clear survival advantage of any combination regimen compared with the simple oral regimen of MP. The respective median overall survival rates were 52 months, 33 months, and 38 months. ${ }^{60} \mathrm{~A}$ separate randomized trial confirmed the superiority of MPT over MP in terms of overall survival ${ }^{64}$ Hulin et al ${ }^{61}$ subsequently confirmed that the survival advantage with MPT compared with MP extends to patients aged 75-85 years as well; median survival 44 versus 29 months, respectively. In contrast to these trials, Waage and colleagues found no PFS or overall survival benefit with MPT compared with MP. ${ }^{63}$ A recent meta-analysis of these five randomized trials shows a clear superiority of MPT in terms of PFS, and a trend towards improved survival. ${ }^{65}$ Grade 3 or 4 adverse events occurred in approximately $55 \%$ of patients treated with MPT compared to $22 \%$ with MP. ${ }^{62}$ There is a significant (20\%) risk of DVT with MPT in the absence of thromboprophylaxis. However, this rate drops to approximately $3 \%$ with thromboprophylaxis. ${ }^{63}$

In phase II studies, VMP was remarkably active with a response rate of almost $90 \%$, and a CR rate of approximately $30 \% .{ }^{66}$ In a phase III trial comparing VMP to MP, the CR rate was $30 \%$ versus $4 \% .{ }^{67,68}$ Time to treatment progression was also significantly superior, 24 months versus 17 months. As with other bortezomib-based regimens, neuropathy is a significant risk with VMP therapy; the rates of grade 1, 2, and 3 neuropathy are $44 \%, 30 \%$, and $13 \%$, respectively. ${ }^{67}$ However, this risk can be greatly decreased if a once-weekly schedule of bortezomib is used, as shown in two phase III trials that compared VMP to bortezomib, thalidomide, prednisone (VTP) ${ }^{43}$ and VMP compared to VMP plus thalidomide (VMPT). ${ }^{69}$ In order to reduce the risk of severe neuropathy, the once weekly 
bortezomib schedule is preferred unless there is an urgent need for rapid disease control. ${ }^{44}$ Subcutaneous dosing may also reduce the risk of neuropathy and is being studied. The response rates and PFS can be improved with the addition of thalidomide to VMP (VMPT), but overall survival improvements have not been observed. ${ }^{69}$

As expected, MPR has shown high activity in phase II studies in newly diagnosed patients aged $\geq 65$ years. ${ }^{70}$ Neuropathy is not a major adverse effect but grade 3 or 4 hematologic adverse events occur, such as neutropenia, thrombocytopenia, and anemia. Preliminary results of a recent phase III trial show no advantage of MPR over MP in terms of PFS. ${ }^{71}$ Although a third arm using MPR followed by lenalidomide maintenance (MPR-R) was superior to either MP or MPR the trial did not resolve whether upfront use of MPR is of value. A randomized trial (E1A06) is currently comparing MPR to MPT.

\section{Hematopoietic stem-cell transplantation}

Autologous stem-cell transplantation-ASCT improves CR rates and prolongs median overall survival in multiple myeloma by approximately 12 months. ${ }^{72,73}$ The mortality rate with ASCT is very low (1-2\%), and a substantial proportion of transplants can be done on an outpatient basis. ${ }^{74}$ Melphalan $200 \mathrm{mg} / \mathrm{m}^{2}$ is the most widely used conditioning regimen for ASCT. Studies are ongoing to determine the benefit of adding bortezomib to the conditioning regimen.

Although ASCT has proven value in multiple myeloma, the timing of transplantation has been a topic of debate. Three randomized trials show that survival is similar whether ASCT is performed immediately after induction therapy or delayed until first relapse. ${ }^{75-77} \mathrm{An}$ ongoing study (NCT01208662) is examining the role of early versus delayed ASCT in the era of novel therapy. A second question is do patients who respond well to induction therapy receive any further benefit with ASCT? Patients responding to induction therapy had similar overall survival and PFS when ASCT was compared with eight cycles of chemotherapy. ${ }^{78}$ This finding suggests that the greatest benefit from ASCT may be in those with disease refractory to induction therapy. A third question concerns the value of a second (tandem) ASCT in patients who have already undergone ASCT shortly after recovery from the first procedure. Three randomized trials suggest superior PFS and survival with tandem ASCT ${ }^{79-81}$ In two trials, the benefit of a second ASCT was restricted to patients failing to achieve a CR or VGPR with the first procedure. ${ }^{79,80}$

Allogeneic transplantation-Only a small proportion of patients are candidates for allogeneic transplantation because of age, availability of a HLA-matched sibling donor, and adequate organ function. The high treatment-related mortality, mainly related to graftversus-host disease (GVHD) has made conventional myeloablative allogeneic transplants unacceptable for most patients. Recent studies have tried to reduce treatment-related mortality using non-myeloablative allografting regimens (mini-allogeneic transplantation; reduced-intensity conditioning allogeneic transplantation). In the newly diagnosed setting such transplants are used with induction therapy and ASCT. The treatment-related mortality is lower than myeloablative transplants, and is approximately $10-15 \%$, but grade $2-4$ acute GVHD occurs in approximately $40 \%$ of patients, and extensive chronic GVHD can occur in over $50 \% .^{82}$

Bruno and colleagues found a significant overall survival advantage with ASCT followed by non-myeloablative allograft compared with tandem ASCT. ${ }^{83}$ Other trials have not shown such a benefit. ${ }^{84-86} \mathrm{~A}$ recent study found no benefit with non-myeloablative allogeneic transplantation compared with ASCT in either high risk or standard-risk patients, ${ }^{87,88}$ dampening the enthusiasm for allogeneic approaches in multiple myeloma. Allogeneic 
approaches for multiple myeloma, both myeloablative and non myeloablative, are currently not recommended outside of clinical trials.

\section{Approaches for newly diagnosed patients Cure versus control}

The approach to the treatment of multiple myeloma varies considerably depending on whether curative intent or chronic disease control is the aim. ${ }^{16}$ Those favoring the curative approach feel that incorporation of all active agents will target the disease at its most vulnerable stage before the development of microenvironmental independence and secondary cytogenetic abnormalities. Those favoring disease control prefer a risk-adapted approach in which an aggressive strategy is pursued for intermediate-risk and high-risk patients, but standard-risk patients are offered an alternative sequential therapy approach that minimizes toxic effects and maximizes quality of life and patient preference. ${ }^{20}$ The reasoning behind the latter approach is the belief that current treatments available are not curative, and while combination strategies improve CR and PFS, overall survival has remained similar compared with sequential approaches. The best available data shows that patients with standard-risk early-stage disease may not benefit from attaining CR, while achieving a CR seems to be critical for patients with high-risk disease. A suggested approach for the treatment of symptomatic newly diagnosed multiple myeloma is outlined in Figure 1.

\section{Approach for standard-risk multiple myeloma}

Standard-risk patients have excellent survival regardless of the sequence of administration of various treatments or the depth of response. ${ }^{89}$ I typically use Rd as initial therapy, and incorporate ASCT early or delayed in eligible patients. This approach has the advantage of eliminating even the smallest possibility of severe neuropathy early in the disease course. ${ }^{14}$ VD is a reasonable alternative in patients pursuing early ASCT but is not ideal for long-term use because even subcutaneous use requires a clinic visit. ${ }^{42}$ Many investigators feel that most treatments work best in the standard-risk population and, therefore, one should offer triplet combinations that have the highest probability of achieving $\mathrm{CR}$ for this patient population. Although surrogate end points such as CR or PFS can be improved by any one of the triplet combinations discussed, there are no data that overall survival with any of the triplet combinations is superior to Rd or VD in phase III trials. However, a triplet combination such as VCD can improve disease control when weekly bortezomib is used and is a reasonable alternative to $\mathrm{VD}$.

In standard-risk patients, the timing of ASCT (early versus delayed) is left to the discretion of the treating physician and is guided by patient choice provided facilities are available for long-term cryopreservation of stem cells. A second ASCT is considered primarily for those not achieving a CR or VGPR with the first ASCT. Data indicate that long-term outcome in standard- risk patients is similar whether patients achieve a CR or not. ${ }^{89}$ Consequently while $\mathrm{CR}$ is desirable, in patients with standard-risk disease any level of response with initial therapy may be adequate for equivalent long-term outcome.

\section{Approach for intermediate-risk multiple myeloma}

Patients with intermediate-risk multiple myeloma require a modified approach to treatment. For example, these patients require bortezomib-based initial therapy in order to overcome the adverse prognostic effect of the t4;14 translocation, whereas patients with standard-risk disease have excellent outcomes overall, and either bortezomib-based or lenalidomide-based induction is reasonable. 
Intermediate-risk patients can have improved outcome if bortezomib is administered early in the disease course, especially in conjunction with ASCT. In the TT3 trial, overall survival for patients with $\mathrm{t}(4 ; 14)$ was identical to patients with hyperdiploidy or $\mathrm{t}(11 ; 14)$, indicating that prolonged (1 year or longer) bortezomib-based therapy with tandem ASCT can completely overcome the poor prognostic effects of this abnormality. ${ }^{90}$ Cavo et al. ${ }^{15}$ also observed this effect when they used VTD followed by ASCT and VTD consolidation. Results with VMP are conflicting, ${ }^{43,67}$ but a short course of VD induction (four cycles) seems to be partially effective. ${ }^{42}$ Based on these data, patients with intermediate-risk multiple myeloma should be treated with a bortezomib-based initial therapy such as VCD, VTD or VRd for approximately 1 year followed by maintenance. ASCT must be considered in all eligible patients.

In intermediate-risk patients, early ASCT is preferred for eligible patients. Post ASCT, bortezomib-based consolidation (VTD or equivalent) and/or maintenance (one dose every 2 weeks) must be considered. ${ }^{91}$ Data suggest a benefit associated with CR primarily for highrisk patients. ${ }^{89}$ However, given the risk of relapse in intermediate-risk patients, a goal of CR or VGPR seems reasonable in this population.

\section{Approach for high-risk multiple myeloma}

The rationale for the approach to high-risk multiple myeloma is based on the evidence that such patients do poorly with most available treatments, and have significantly inferior survival in the absence of CR. Patients with high-risk disease tend to have a median overall survival of approximately 3 years, even with an aggressive treatment approach that includes VDT-PACE induction, tandem ASCT, consolidation, and VRd maintenance. ${ }^{87}$ Therefore, these patients must be specifically recruited to clinical trials investigating novel therapies. Although none of the therapies available seems to overcome high-risk multiple myeloma, the most promising is VRd with or without additional novel agents. ${ }^{47}$

The role of ASCT is controversial. The Arkansas study suggests that high-risk patients (despite tandem ASCT) gain only a modest survival improvement in absolute terms. ${ }^{90}$ ASCT is reasonable especially if patients do not achieve CR within four to six cycles of VRd or other induction therapy. In addition to ASCT, for those under the age of 50 years, myeloablative allogeneic transplantation might be an option in selected patients willing to accept a high treatment-related mortality in exchange for a small probability of long-term (10 years or longer) survival. Clearly, clinical trials and new agents specifically designed for high-risk disease are needed. In patients with high-risk disease CR should be pursued as a definitive treatment goal. ${ }^{89}$ This may require change of treatment regimens in patients who do not achieve CR.

\section{Maintenance therapy}

Prior to the arrival of thalidomide, lenalidomide and bortezomib, clinical trials evaluated interferon- $\alpha$ and corticosteroids as maintenance therapy. However, these approaches were not widely accepted because of relatively modest benefit and the toxic effects associated with treatment. Results of recent studies investigating maintenance therapy are summarized below.

\section{Options for maintenance therapy}

Thalidomide - In a French trial, patients who had ACST were randomly assigned to no maintenance (arm A), pamidronate (arm B), or pamidronate plus thalidomide $(\operatorname{arm} C) .{ }^{92}$ There was a significant survival improvement, with 4-year survival rates of $77 \%, 74 \%$, and $87 \%$, respectively. A similar benefit was also noted by Spencer et al. ${ }^{93}$ who randomized 
patients post ASCT to thalidomide consolidation (for 12 months) plus indefinite prednisolone versus indefinite prednisolone. Overall survival at 3 years was better with thalidomide ( $86 \%$ versus $75 \%$ ). By contrast, a study conducted in Canada did not find a significant survival benefit, ${ }^{94}$ while a trial by Sonneveld and colleagues found superior survival with bortezomib compared with thalidomide. ${ }^{91}$

Lenalidomide-The feasibility and potential effectiveness of lenalidomide maintenance after induction and ASCT has been established. ${ }^{94}$ Two recent randomized studies have subsequently shown prolongation of remission duration when lenalidomide is used as maintenance therapy post ASCT. Attal and colleagues treated patients after first-line ASCT with lenalidomide consolidation ( $25 \mathrm{mg}$ days 1-21 every 28 days) for 2 months followed by randomization to lenalidomide (10-15 mg/day) or placebo. ${ }^{95} \mathrm{PFS}$ was significantly superior with lenalidomide maintenance; 3 -year PFS $68 \%$ versus $34 \%$. In another study, the Cancer and Acute Leukemia Group B observed superior PFS with maintenance lenalidomide compared with placebo. ${ }^{96}$ In both studies, no overall survival differences were observed. Although lenalidomide maintenance was well tolerated, there was an increased number of second malignancies in the lenalidomide treatment arms in both trials. Data from trials are being carefully examined to determine if there are potential confounding factors, to clarify the effect of maintenance duration, and to ensure that there is accurate ascertainment of second cancers in the control arm.

Bortezomib-A study by Sonneveld et al. ${ }^{91}$ found that bortezomib administered once every 2 weeks as maintenance therapy prolonged PFS and overall survival in multiple myeloma compared with thalidomide. These are provocative data, and lend support at least for the routine use of bortezomib in patients with intermediate-risk and high-risk disease, since the adverse effects of some cytogenetic abnormalities can be partially overcome when bortezomib is used for approximately 1 year following the initial diagnosis of multiple myeloma. ${ }^{15,90}$

\section{Role of maintenance therapy}

The role of maintenance therapy remains controversial. In patients with intermediate-risk and high-risk disease, maintenance therapy can be justified based on the high risk of relapse, and bortezomib is the preferred agent for maintenance based on existing data. In standardrisk patients, we need to await evidence of an overall survival benefit as well as more data on the risk of second cancers before recommending routine lenalidomide maintenance for all patients; more data regarding the efficacy of bortezomib are also needed. It is reasonable, however, to consider lenalidomide maintenance for the subset of standard-risk patients who do not achieve CR or VGPR with ASCT. Such therapy is typically considered 'consolidation' rather than maintenance and is usually given for a defined period of time (12-24 months). The benefits and risks of lenalidomide immediately following ASCT versus lenalidomide therapy at first relapse must be discussed with patients.

\section{Treatment of relapsed multiple myeloma}

Almost all patients with multiple myeloma eventually relapse. The remission duration in relapsed multiple myeloma decreases with each regimen successively used. ${ }^{97}$ In patients with relapsed multiple myeloma refractory to lenalidomide and bortezomib, median PFS and overall survival is poor, with median times of 5 months and 9 months, respectively. ${ }^{98}$ A full assessment of the treatment of relapsed multiple myeloma is beyond the scope of this Review, but some general principles can be considered. First, patients who have cryopreserved stem cells early in the disease course can derive considerable benefit from ASCT as salvage therapy. Second, patients with indolent disease who have a relapse can be 
treated with any of the doublet combinations for newly diagnosed multiple myeloma. By contrast, patients with more-aggressive relapse often require therapy with one of the triplet combinations. Finally, patients occasionally present with multiple plasmacytomas or plasma cell leukemia at relapse, ${ }^{99}$ and such patients may require initial therapy with a multidrug regimen such as VDT-PACE.

\section{New agents}

Although many new agents are being studied in multiple myeloma, only pomalidomide and carfilzomib have shown significant single-agent activity in clinical trials and are likely to be approved by regulatory authorities in the near future. These two agents have promising activity and are in phase III testing.

Pomalidomide is an immunomodulatory analog of thalidomide and lenalidomide. Schey and colleagues assessed pomalidomide and showed it had remarkable single-agent activity in a small phase I trial in relapsed, refractory multiple myeloma. ${ }^{100}$ Lacy and colleagues established that the combination of pomalidomide ( $2 \mathrm{mg}$ daily oral) plus low-dose dexamethasone (40 mg once weekly oral) is remarkably active in patients with relapsed multiple myeloma, with response rates of over $60 \% .{ }^{101}$ Additional trials are ongoing to explore other dosing schedules. ${ }^{47,102}$ Given its single-agent activity, and excellent tolerability it is likely that pomalidomide will be approved in the near future for relapsed refractory multiple myeloma.

Carfilzomib is a novel keto-epoxide tetrapeptide proteasome inhibitor that has potent singleagent activity in relapsed, refractory multiple myeloma. Unlike bortezomib that has a slow reversible effect on the proteasome, carfilzomib is a highly selective irreversible proteasome inhibitor that binds specifically to the N-terminal threonine active sites of the proteasome. While bortezomib inhibits both chymotrypsin-like and caspase-like activities of the proteasome, carfilzomib is more selective for the chymotrypsin-like active site within the proteasome, which may result in greater specificity and lower toxic effects. In a phase II study partial response or better was achieved in 23 of 51 (45\%) bortezomib-naive patients with relapsed multiple myeloma. ${ }^{103}$ Response rates were lower in patients previously treated with bortezomib (approximately 20\%) or refractory to bortezomib (approximately 15\%). The rate of severe neuropathy is low with carfilzomib making this an attractive agent for relapsed or refractory multiple myeloma. ${ }^{103} \mathrm{~A}$ phase III trial is comparing carfilzomib plus $\mathrm{Rd}$ to $\mathrm{Rd}$ alone in relapsed multiple myeloma. It is likely that carfilzomib will be approved for the treatment of relapsed multiple myeloma in the near future.

\section{Other promising drugs}

Besides carfilzomib and pomalidomide, the most promising drugs in advanced clinical trials in multiple myeloma include histone deacetylase inhibitors (vorinostat and panobinostat), and the anti-CS1 antibody, elotuzumab (Table 6). ${ }^{104}$ However, none of these agents has significant single-agent activity, and their treatment impact long term is unclear.

\section{Conclusions and future directions}

Survival in multiple myeloma has improved significantly in the past 10 years. ${ }^{105}$ Besides the new treatment options discussed herein, advances in supportive care, especially with bisphosphonates, have also made a major difference. ${ }^{35}$ The treatment of multiple myeloma remains challenging, and despite numerous advances, further improvements and several paradigm shifts are needed (Table 7). The main barrier is that we have not yet identified key pathogenetic events analogous to BCR-ABL in chronic myelogenous leukemia. In the near future, we need new classes of drugs active against the disease that can be effectively 
combined with existing active classes, namely alkylators, immunomodulatory agents, corticosteroids, and proteasome inhibitors.

\section{References}

1. Kyle RA, Rajkumar SV. Multiple myeloma. N Engl J Med. 2004; 351:1860-1873. [PubMed: 15509819]

2. Rajkumar SV, Kyle RA. Multiple myeloma: diagnosis and treatment. Mayo Clin Proc. 2005; 80:1371-1382. [PubMed: 16212152]

3. Jemal A, Siegel R, Xu J, Ward E. Cancer statistics, 2010. CA Cancer J Clin. 2010; 60:277-300. [PubMed: 20610543]

4. Landgren O, Weiss BM. Patterns of monoclonal gammopathy of undetermined significance and multiple myeloma in various ethnic/racial groups: support for genetic factors in pathogenesis. Leukemia. 2009; 23:1691-1697. [PubMed: 19587704]

5. Kyle RA, Rajkumar SV. Criteria for diagnosis, staging, risk stratification and response assessment of multiple myeloma. Leukemia. 2009; 23:3-9. [PubMed: 18971951]

6. Landgren $\mathrm{O}$, et al. Monoclonal gammopathy of undetermined significance (MGUS) consistently precedes multiple myeloma: a prospective study. Blood. 2009; 113:5412-5417. [PubMed: 19179464]

7. Kyle RA, et al. A long-term study of prognosis of monoclonal gammopathy of undetermined significance. N Engl J Med. 2002; 346:564-569. [PubMed: 11856795]

8. Kyle RA, et al. Prevalence of monoclonal gammopathy of undetermined significance. N Engl J Med. 2006; 354:1362-1369. [PubMed: 16571879]

9. Tian E, et al. The role of the Wnt-signaling antagonist DKK1 in the development of osteolytic lesions in multiple myeloma. N Engl J Med. 2003; 349:2483-2494. [PubMed: 14695408]

10. Singhal S, et al. Antitumor activity of thalidomide in refractory multiple myeloma. N Engl J Med. 1999; 341:1565-1571. [PubMed: 10564685]

11. Richardson PG, et al. Bortezomib or high-dose dexamethasone for relapsed multiple myeloma. $\mathrm{N}$ Engl J Med. 2005; 352:2487-2498. [PubMed: 15958804]

12. Rajkumar SV, et al. Combination therapy with lenalidomide plus dexamethasone (Rev/Dex) for newly diagnosed myeloma. Blood. 2005; 106:4050-4053. [PubMed: 16118317]

13. Richardson PG, et al. A randomized phase 2 study of lenalidomide therapy for patients with relapsed or relapsed and refractory multiple myeloma. Blood. 2006; 108:3458-3464. [PubMed: 16840727]

14. Rajkumar SV, et al. Lenalidomide plus high-dose dexamethasone versus lenalidomide plus lowdose dexamethasone as initial therapy for newly diagnosed multiple myeloma: an open-label randomised controlled trial. Lancet Oncol. 2010; 11:29-37. [PubMed: 19853510]

15. Cavo M, et al. Bortezomib-thalidomide-dexamethasone compared with thalidomidedexamethasone as induction and consolidation therapy before and after double autologous transplantation in newly diagnosed multiple myeloma: results from a randomized phase 3 study [abstract]. Blood. 2010; 116 (ASH Annual Meeting Abstracts):a42.

16. Rajkumar SV. Treatment of myeloma: cure vs control. Mayo Clin Proc. 2008; 83:1142-1145. [PubMed: 18828974]

17. Durie BG, Salmon SE. A clinical staging system for multiple myeloma. Correlation of measured myeloma cell mass with presenting clinical features, response to treatment, and survival. Cancer. 1975; 36:842-854. [PubMed: 1182674]

18. Greipp PR, et al. International staging system for multiple myeloma. J Clin Oncol. 2005; 23:34123420. [PubMed: 15809451]

19. Fonseca R, et al. International Myeloma Working Group molecular classification of multiple myeloma: spotlight review. Leukemia. 2009; 23:2210-2221. [PubMed: 19798094]

20. Kumar SK, et al. Management of newly diagnosed symptomatic multiple myeloma: updated Mayo Stratification of Myeloma and Risk-Adapted Therapy (mSMART) consensus guidelines. Mayo Clin Proc. 2009; 84:1095-1110. [PubMed: 19955246] 
21. Zhou Y, Barlogie B, Shaughnessy JD Jr. The molecular characterization and clinical management of multiple myeloma in the postgenome era. Leukemia. 2009; 23:1941-1956. [PubMed: 19657360]

22. Kyle RA, et al. Clinical course and prognosis of smoldering (asymptomatic) multiple myeloma. $\mathrm{N}$ Engl J Med. 2007; 356:2582-2590. [PubMed: 17582068]

23. Rajkumar SV. Prevention of progression in monoclonal gammopathy of undetermined significance. Clin Cancer Res. 2009; 15:5606-5608. [PubMed: 19737944]

24. Hjorth M, et al. Initial versus deferred melphalan-prednisone therapy for asymptomatic multiple myeloma stage I--a randomized study. Myeloma Group of Western Sweden. Eur J Haematol. 1993; 50:95-102. [PubMed: 8440364]

25. Riccardi A, et al. Long-term survival of stage I multiple myeloma given chemotherapy just after diagnosis or at progression of the disease: a multicentre randomized study. Cooperative Group of Study and Treatment of Multiple Myeloma. Br J Cancer. 2000; 82:1254-1260. [PubMed: 10755397]

26. Mateos MV, et al. Multicenter, randomized, open-label, phase III trial of lenalidomidedexamethasone (len/dex) vs therapeutic abstention in smoldering multiple myeloma at high risk of progression to symptomatic MM: results of the first interim analysis [abstract]. Blood. 2009; 114 (ASH Annual Meeting Abstracts):a614.

27. Kumar S, et al. Mobilization in myeloma revisited: IMWG consensus perspectives on stem cell collection following initial therapy with thalidomide-, lenalidomide-, or bortezomib-containing regimens. Blood. 2009; 114:1729-1735. [PubMed: 19561323]

28. Rajkumar SV, et al. Combination therapy with thalidomide plus dexamethasone for newly diagnosed myeloma. J Clin Oncol. 2002; 20:4319-4323. [PubMed: 12409330]

29. Weber DM, et al. Thalidomide alone or with dexamethasone for multiple myeloma [abstract]. Blood. 1999; 94 (Suppl 1):604a.

30. Cavo M, et al. First-line therapy with thalidomide and dexamethasone in preparation for autologous stem cell transplantation for multiple myeloma. Haematologica. 2004; 89:826-831. [PubMed: 15257934]

31. Rajkumar SV, Blood E, Vesole DH, Fonseca R, Greipp PR. Phase III clinical trial of thalidomide plus dexamethasone compared with dexamethasone alone in newly diagnosed multiple myeloma: a clinical trial coordinated by the Eastern Cooperative Oncology Group. J Clin Oncol. 2006; 24:431-436. [PubMed: 16365178]

32. Rajkumar SV, et al. Multicenter, randomized, double-blind, placebo-controlled study of thalidomide plus dexamethasone compared with dexamethasone as initial therapy for newly diagnosed multiple myeloma. J Clin Oncol. 2008; 26:2171-2177. [PubMed: 18362366]

33. Ludwig H, et al. Thalidomide-dexamethasone compared with melphalan-prednisolone in elderly patients with multiple myeloma. Blood. 2009; 113:3435-3442. [PubMed: 18955563]

34. Gay F, et al. Lenalidomide plus dexamethasone versus thalidomide plus dexamethasone in newly diagnosed multiple myeloma: a comparative analysis of 411 patients. Blood. 2010; 115:13431350. [PubMed: 20008302]

35. Morgan GJ, et al. First-line treatment with zoledronic acid as compared with clodronic acid in multiple myeloma (MRC Myeloma IX): a randomised controlled trial. Lancet. 2010; 376:19891999. [PubMed: 21131037]

36. Palumbo A, et al. A phase III study of enoxaparin vs aspirin vs low-dose warfarin as thromboprophylaxis for newly diagnosed myeloma patients treated with thalidomide basedregimens [abstract]. Blood. 2009; 114 (ASH Annual Meeting Abstracts):a492.

37. Palumbo A, et al. Prevention of thalidomide- and lenalidomide-associated thrombosis in myeloma. Leukemia. 2008; 22:414-423. [PubMed: 18094721]

38. Zonder JA, et al. Lenalidomide and high-dose dexamethasone compared with dexamethasone as initial therapy for multiple myeloma: a randomized Southwest Oncology Group trial (S0232). Blood. 2010; 116:5838-5841. [PubMed: 20876454]

39. Kumar S, et al. Impact of lenalidomide therapy on stem cell mobilization and engraftment postperipheral blood stem cell transplantation in patients with newly diagnosed myeloma. Leukemia. 2007; 21:2035-2042. [PubMed: 17581613] 
40. Harousseau JL, et al. Bortezomib plus dexamethasone as induction treatment prior to autologous stem cell transplantation in patients with newly diagnosed multiple myeloma: results of an IFM phase II study. Haematologica. 2006; 91:1498-1505. [PubMed: 17043025]

41. Jagannath $\mathrm{S}$, et al. Bortezomib therapy alone and in combination with dexamethasone for previously untreated symptomatic multiple myeloma. Br J Haematol. 2005; 129:776-783. [PubMed: 15953004]

42. Harousseau JL, et al. Bortezomib plus dexamethasone is superior to vincristine plus doxorubicin plus dexamethasone as induction treatment prior to autologous stem-cell transplantation in newly diagnosed multiple myeloma: results of the IFM 2005-01 phase III trial. J Clin Oncol. 2010; 28:4621-4629. [PubMed: 20823406]

43. Mateos MV, et al. Bortezomib, melphalan, and prednisone versus bortezomib, thalidomide, and prednisone as induction therapy followed by maintenance treatment with bortezomib and thalidomide versus bortezomib and prednisone in elderly patients with untreated multiple myeloma: a randomised trial. Lancet Oncol. 2010; 11:934-941. [PubMed: 20739218]

44. Rajkumar SV. Optimising bortezomib in newly diagnosed multiple myeloma. Lancet Oncol. 2010; 11:909-910. [PubMed: 20739219]

45. San-Miguel J, Harousseau JL, Joshua D, Anderson KC. Individualizing treatment of patients with myeloma in the era of novel agents. J Clin Oncol. 2008; 26:2761-2766. [PubMed: 18427148]

46. Moreau P, et al. Comparison of reduced-dose bortezomib plus thalidomide plus dexamethasone to bortezomib plus dexamethasone as induction treatment prior to ASCT in de novo multiple myeloma: Results of IFM2007-02 study [abstract]. J Clin Oncol. 2010; 28 (Suppl):a8014.

47. Richardson PG, et al. Lenalidomide, bortezomib, and dexamethasone combination therapy in patients with newly diagnosed multiple myeloma. Blood. 2010; 116:679-686. [PubMed: 20385792]

48. US National Library of Medicine. ClinicalTrialsgov. 2010. [online], http://clinicaltrials.gov/ct2/ show/NCT01208662

49. Reeder CB, et al. Cyclophosphamide, bortezomib and dexamethasone induction for newly diagnosed multiple myeloma: high response rates in a phase II clinical trial. Leukemia. 2009; 23:1337-1341. [PubMed: 19225538]

50. Kumar S, et al. Novel three- and four-drug combination regimens of bortezomib, dexamethasone, cyclophosphamide, and lenalidomide, for previously untreated multiple myeloma: results from the multi-center, randomized, phase 2 EVOLUTION study [abstract]. Blood. 2010; 116 (ASH Annual Meeting Abstracts):a621.

51. Lokhorst HM, et al. A randomized phase 3 study on the effect of thalidomide combined with adriamycin, dexamethasone, and high-dose melphalan, followed by thalidomide maintenance in patients with multiple myeloma. Blood. 2010; 115:1113-1120. [PubMed: 19880501]

52. Jakubowiak AJ, et al. Phase II trial of combination therapy with bortezomib, pegylated liposomal doxorubicin, and dexamethasone in patients with newly diagnosed myeloma. J Clin Oncol. 2009; 27:5015-5022. [PubMed: 19738129]

53. Barlogie B, et al. Incorporating bortezomib into upfront treatment for multiple myeloma: early results of total therapy 3. Br J Haematol. 2007; 138:176-185. [PubMed: 17593024]

54. Kumar SK, et al. Bortezomib, dexamethasone, cyclophosphamide and lenalidomide combination for newly diagnosed multiple myeloma: phase 1 results from the multicenter EVOLUTION study. Leukemia. 2010; 24:1350-1356. [PubMed: 20508619]

55 . Jacobus $\mathrm{S}$, et al. Outcome of elderly patients 70 years and older with newly diagnosed myeloma in the ECOG randomized trial of lenalidomide/high-dose dexamethasone (RD) versus lenalidomide/ low-dose dexamethasone (Rd) [abstract 0370]. Haematologica. 2010; 95 (Suppl 2):149.

56. Gay F, et al. Safety and efficacy of lenalidomide plus dexamethasone in elderly newly diagnosed multiple myeloma patients 70 years of age and older [abstract 0379]. Haematologica. 2010; 95 (Suppl 2):153. [PubMed: 19648161]

57. Combination chemotherapy versus melphalan plus prednisone as treatment for multiple myeloma: an overview of 6, 633 patients from 27 randomized trials. Myeloma Trialists' Collaborative Group. J Clin Oncol. 1998; 16:3832-3842. [No authors listed]. [PubMed: 9850028]

58. Kyle RA, Rajkumar SV. Multiple myeloma. Blood. 2008; 111:2962-2972. [PubMed: 18332230] 
59. Facon T, et al. Dexamethasone-based regimens versus melphalan-prednisone for elderly multiple myeloma patients ineligible for high-dose therapy. Blood. 2006; 107:1292-1298. [PubMed: 16174762]

60. Facon T, et al. Melphalan and prednisone plus thalidomide versus melphalan and prednisone alone or reduced-intensity autologous stem cell transplantation in elderly patients with multiple myeloma (IFM 99-06): a randomised trial. Lancet. 2007; 370:1209-1218. [PubMed: 17920916]

61. Hulin C, et al. Efficacy of melphalan and prednisone plus thalidomide in patients older than 75 years with newly diagnosed multiple myeloma: IFM 01/01 trial. J Clin Oncol. 2009; 27:36643670. [PubMed: 19451428]

62. Palumbo A, et al. Oral melphalan and prednisone chemotherapy plus thalidomide compared with melphalan and prednisone alone in elderly patients with multiple myeloma: randomised controlled trial. Lancet. 2006; 367:825-831. [PubMed: 16530576]

63. Waage A, et al. Melphalan and prednisone plus thalidomide or placebo in elderly patients with multiple myeloma. Blood. 2010; 116:1405-1412. [PubMed: 20448107]

64. Wijermans P, et al. Phase III study of the value of thalidomide added to melphalan plus prednisone in elderly patients with newly diagnosed multiple myeloma: the HOVON 49 Study. J Clin Oncol. 2010; 28:3160-3166. [PubMed: 20516439]

65. Kapoor P, et al. Melphalan and prednisone (MP) versus melphalan, prednisone and thalidomide (MPT) as initial therapy for previously untreated elderly and/or transplant ineligible patients with multiple myeloma: a meta-analysis of randomized controlled trials [abstract]. Blood. 2009; 114 (ASH Annual Meeting Abstracts):a615.

66. Mateos MV, et al. Bortezomib plus melphalan and prednisone in elderly untreated patients with multiple myeloma: results of a multicenter phase 1/2 study. Blood. 2006; 108:2165-2172. [PubMed: 16772605]

67. San Miguel JF, et al. Bortezomib plus melphalan and prednisone for initial treatment of multiple myeloma. N Engl J Med. 2008; 359:906-917. [PubMed: 18753647]

68. Mateos MV, et al. Bortezomib plus melphalan and prednisone compared with melphalan and prednisone in previously untreated multiple myeloma: updated follow-up and impact of subsequent therapy in the phase III VISTA trial. J Clin Oncol. 2010; 28:2259-2266. [PubMed: 20368561]

69. Palumbo A, et al. Bortezomib-melphalan-prednisone- thalidomide followed by maintenance with bortezomib-thalidomide compared with bortezomib-melphalan-prednisone for initial treatment of multiple myeloma: a randomized controlled trial. J Clin Oncol. 2010; 28:5101-5109. [PubMed: 20940200]

70. Palumbo A, et al. Melphalan, prednisone, and lenalidomide treatment for newly diagnosed myeloma: a report from the GIMEMA-Italian Multiple Myeloma Network. J Clin Oncol. 2007; 25:4459-4465. [PubMed: 17785703]

71. Palumbo A, et al. A phase 3 study evaluating the efficacy and safety of lenalidomide combined with melphalan and prednisone in patients $\searrow 65$ years with newly diagnosed multiple myeloma (NDMM): continuous use of lenalidomide vs fixed-duration regimens [abstract]. Blood. 2010; 116 (ASH Annual Meeting Abstracts):a622.

72. Attal M, et al. A prospective, randomized trial of autologous bone marrow transplantation and chemotherapy in multiple myeloma. Intergroupe Français du Myélome. N Engl J Med. 1996; 335:91-97. [PubMed: 8649495]

73. Child JA, et al. High-dose chemotherapy with hematopoietic stem-cell rescue for multiple myeloma. N Engl J Med. 2003; 348:1875-1883. [PubMed: 12736280]

74. Gertz MA, et al. Autologous stem cell transplantation in 716 patients with multiple myeloma: low treatment-related mortality, feasibility of outpatient transplantation, and effect of a multidisciplinary quality initiative. Mayo Clin Proc. 2008; 83:1131-1138. [PubMed: 18828972]

75. Barlogie B, et al. Standard chemotherapy compared with high-dose chemoradiotherapy for multiple myeloma: final results of phase III US Intergroup Trial S9321. J Clin Oncol. 2006; 24:929-936. [PubMed: 16432076] 
76. Facon T, et al. Front-line or rescue autologous bone marrow transplantation (ABMT) following a first course of high dose melphalan (HDM) in multiple myeloma (MM): preliminary results of a prospective randomized trial (CIAM) protocol [abstract]. Blood. 1996; 88 (Suppl 1):a2729.

77. Fermand JP, et al. High-dose therapy and autologous peripheral blood stem cell transplantation in multiple myeloma: up-front or rescue treatment? Results of a multicenter sequential randomized clinical trial. Blood. 1998; 92:3131-3136. [PubMed: 9787148]

78. Blade J, et al. High-dose therapy autotransplantation/intensification versus continued conventional chemotherapy in multiple myeloma patients responding to initial chemotherapy: definitive results from PETHEMA after a median follow-up of 66 months [abstract]. Blood. 2003; 102:a137.

79. Attal M, et al. Double autologous transplantation improves survival of multiple myeloma patients: final analysis of a prospective randomized study of the "Intergroupe Francophone du Myelome" (IFM 94) [abstract]. Blood. 2002; 100:a7.

80. Cavo M, et al. Superiority of double over single autologous stem cell transplantation as first-line therapy for multiple myeloma [abstract]. Blood. 2004; 104:a536.

81. Regelink JC, et al. Long-term follow-up of tandem autologous stem-cell transplantation in multiple myeloma. J Clin Oncol. 2010; 28:e741-e743. [PubMed: 21060027]

82. Maloney DG, et al. Allografting with nonmyeloablative conditioning following cytoreductive autografts for the treatment of patients with multiple myeloma. Blood. 2003; 102:3447-3454. [PubMed: 12855572]

83. Bruno B, et al. A comparison of allografting with autografting for newly diagnosed myeloma. $\mathrm{N}$ Engl J Med. 2007; 356:1110-1120. [PubMed: 17360989]

84. Garban F, et al. Prospective comparison of autologous stem cell transplantation followed by dosereduced allograft (IFM99-03 trial) with tandem autologous stem cell transplantation (IFM99-04 trial) in high-risk de novo multiple myeloma. Blood. 2006; 107:3474-3480. [PubMed: 16397129]

85. Gahrton G, et al. Tandem autologous(ASCT)/allogeneic reduced intensity conditioning transplantation (RIC) with identical sibling donor versus ASCT in previously untreated multiple myeloma (MM): long term follow up of a prospective controlled trial by the EBMT [abstract]. Blood. 2009; 114 (ASH Annual Meeting Abstracts):a52.

86. Rosiñol L, et al. A prospective PETHEMA study of tandem autologous transplantation versus autograft followed by reduced-intensity conditioning allogeneic transplantation in newly diagnosed multiple myeloma. Blood. 2008; 112:3591-3593. [PubMed: 18612103]

87. Krishnan A, et al. Tandem autologous hematopoietic stem cell transplants (AuHCT) with or without maintenance therapy (auto-auto) versus single AuHCT followed by HLA matched sibling non- myeloablative allogeneic HCT (auto-allo) for patients with standard risk (SR) multiple myeloma (MM): results from the Blood and Marrow Transplant Clinical Trials Network (BMT CTN) 0102 trial [abstract]. Blood. 2010; 116 (ASH Annual Meeting Abstracts):a41.

88. Stadtmauer EA, et al. Tandem autologous stem cell transplants (auto-auto) with or without maintenance therapy versus single autologous transplant followed by HLA-matched sibling nonmyeloablative allogeneic stem cell transplant (auto-allo) for patients (pts) with high risk (HR) multiple myeloma (MM): results from the Blood and Marrow Transplant Clinical Trials Network (BMT-CTN) 0102 trial [abstract]. Blood. 2010; 116 (ASH Annual Meeting Abstracts):a526.

89. Haessler J, et al. Benefit of complete response in multiple myeloma limited to high-risk subgroup identified by gene expression profiling. Clin Cancer Res. 2007; 13:7073-7079. [PubMed: 18056185]

90. Nair B, et al. Superior results of Total Therapy 3 (2003-2033) in gene expression profiling-defined low-risk multiple myeloma confirmed in subsequent trial 2006-66 with VRD maintenance. Blood. 2010; 115:4168-4173. [PubMed: 20124509]

91. Sonneveld P, et al. HOVON-65/GMMG-HD4 randomized phase III trial comparing bortezomib, doxorubicin, dexamethasone (PAD) vs VAD followed by high-dose melphalan (HDM) and maintenance with bortezomib or thalidomide in patients with newly diagnosed multiple myeloma (MM) [abstract]. Blood. 2010; 116 (ASH Annual Meeting Abstracts):a40.

92. Attal M, et al. Maintenance therapy with thalidomide improves survival in patients with multiple myeloma. Blood. 2006; 108:3289-3294. [PubMed: 16873668] 
93. Spencer A, et al. Consolidation therapy with low-dose thalidomide and prednisolone prolongs the survival of multiple myeloma patients undergoing a single autologous stem-cell transplantation procedure. J Clin Oncol. 2009; 27:1788-1793. [PubMed: 19273705]

94. Stewart AK, et al. A randomized phase III trial of thalidomide and prednisone as maintenance therapy following autologous stem cell transplantation (ASCT) in patients with multiple myeloma (MM): the NCIC CTG MY.10 trial [abstract]. Blood. 2010; 116 (ASH Annual Meeting Abstracts):a39.

95. Attal M, et al. Maintenance treatment with lenalidomide after transplantation for MYELOMA: final analysis of the IFM 2005-02 [abstract]. Blood. 2010; 116 (ASH Annual Meeting Abstracts):a310.

96. McCarthy PL, et al. Phase III intergroup study of lenalidomide versus placebo maintenance therapy following single autologous hematopoietic stem cell transplantation (AHSCT) for multiple myeloma: CALGB 100104 [abstract]. Blood. 2010; 116 (ASH Annual Meeting Abstracts):a37.

97. Kumar SK, et al. Clinical course of patients with relapsed multiple myeloma. Mayo Clin Proc. 2004; 79:867-874. [PubMed: 15244382]

98. Kumar S, et al. Outcome of patients with myeloma relapsing after IMiD and bortezomib therapy: a multicenter study from the International Myeloma Foundation Working Group [abstract 0376]. Haematologica. 2010; 95 (Suppl 2):151.

99. Tiedemann RE, et al. Genetic aberrations and survival in plasma cell leukemia. Leukemia. 2008; 22:1044-1052. [PubMed: 18216867]

100. Schey SA, et al. Phase I study of an immunomodulatory thalidomide analog, CC-4047, in relapsed or refractory multiple myeloma. J Clin Oncol. 2004; 22:3269-3276. [PubMed: 15249589]

101. Lacy MQ, et al. Pomalidomide (CC4047) plus low-dose dexamethasone as therapy for relapsed multiple myeloma. J Clin Oncol. 2009; 27:5008-5014. [PubMed: 19720894]

102. Leleu X, et al. Phase 2 study of 2 modalities of pomalidomide (CC4047) plus low-dose dexamethasone as therapy for relapsed multiple myeloma. IFM 2009-02 [abstract]. Blood. 2010; 116 (ASH Annual Meeting Abstracts):a859.

103. Wang L, et al. Updated results of bortezomib-naive patients in PX-171-004, an ongoing openlabel, phase II study of single-agent carfilzomib (CFZ) in patients with relapsed or refractory myeloma (MM) [abstract]. Blood. 2009; 114 (ASH Annual Meeting Abstracts):a302.

104. Laubach JP, et al. The use of novel agents in the treatment of relapsed and refractory multiple myeloma. Leukemia. 2009; 23:2222-2232. [PubMed: 19741729]

105. Kumar SK, et al. Improved survival in multiple myeloma and the impact of novel therapies. Blood. 2008; 111:2516-2520. [PubMed: 17975015] 


\section{Key points}

- The treatment of multiple myeloma has changed dramatically in the past decade with several new active agents and numerous possible drug combinations

- Based on specific cytogenetic features, myeloma can be classified into high, intermediate, and standard-risk categories

- Patients with $17 \mathrm{p}$ deletion, $\mathrm{t}(14 ; 16)$, and $\mathrm{t}(14 ; 20)$ are considered to have highrisk disease, while those with $\mathrm{t}(4 ; 14)$ in the absence of high-risk features represent intermediate-risk disease

- Two and three drug combinations incorporating immunomodulatory agents (thalidomide, lenalidomide) and/or bortezomib are the mainstay of initial therapy

- The intensity and duration of treatment is dictated by the baseline risk stratification and eligibility for stem-cell transplantation; autologous stem-cell transplantation is not curative but prolongs survival

- The most promising new agents include pomalidomide, carfilzomib, elotuzumab, MLN9708, histone deacetylase inhibitors, PI3K pathway inhibitors, and heat shock protein 90 inhibitors 


\section{Review criteria}

A systematic literature search of the PubMed database was completed to identify all studies investigating the treatment of multiple myeloma. The following MeSH search terms were used: "multiple myeloma and treatment", "multiple myeloma and randomized trials", "multiple myeloma and therapy", and "multiple myeloma and transplantation". Abstracts published from the annual meetings of the American Society of Hematology, ASCO, and the European Hematology Association in 2008, 2009 and 2010 were reviewed for the same criteria. Articles were limited to those written in English and published before 1 December 2010. 
a
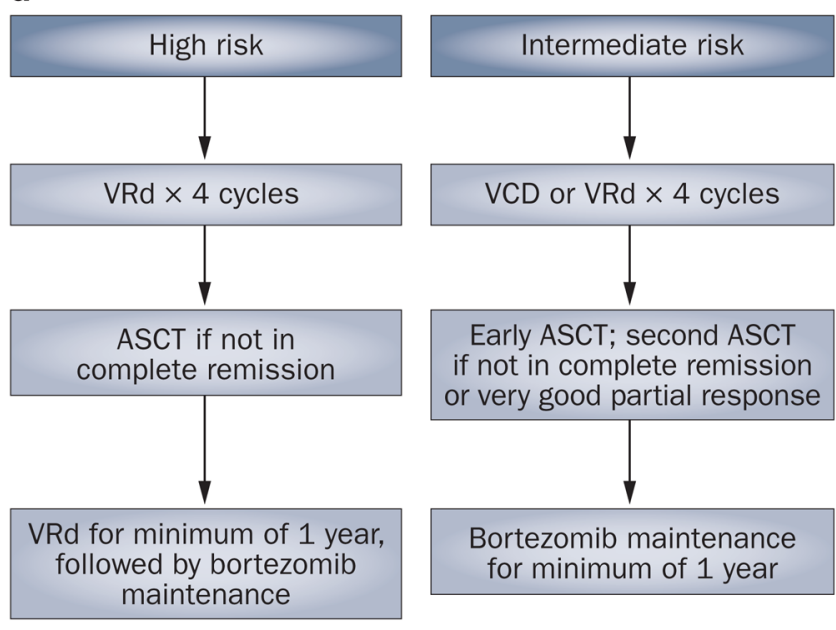

Early ASCT; second ASCT

if not in complete remission or very good partial response

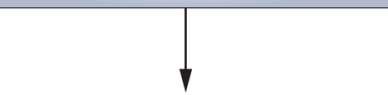

Bortezomib maintenance for minimum of 1 year

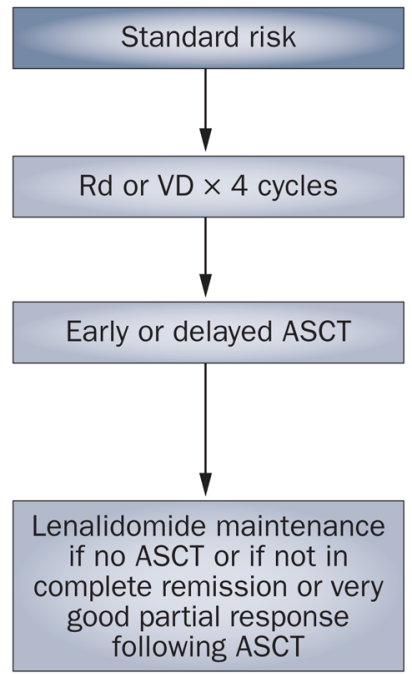

b
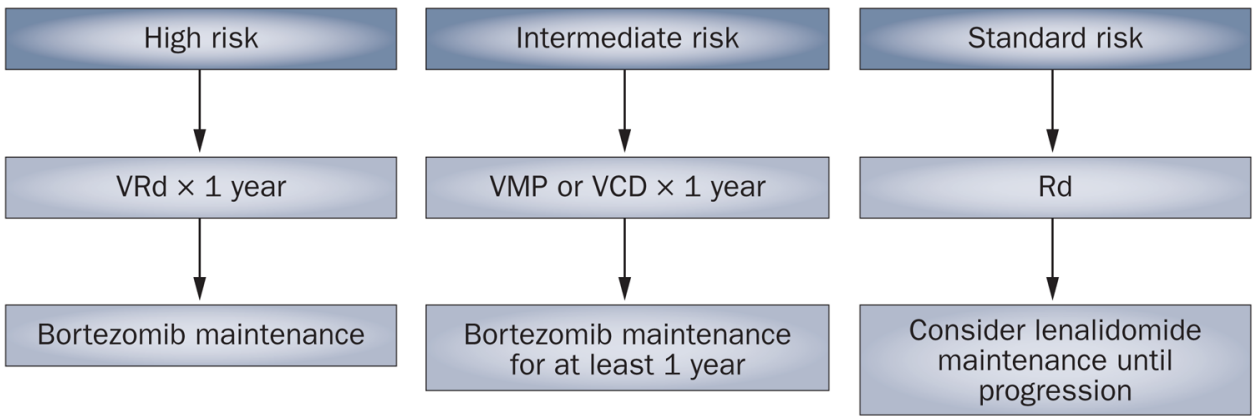

Figure 1.

Treatment algorithm $\mathbf{a}$ | Treatment approach for newly diagnosed transplant candidates. $\mathbf{b}$ | Treatment approach for newly diagnosed elderly, nontransplant candidates. Abbreviations: ASCT, autologous stem-cell transplantation; CR, complete response; VCD, bortezomibcyclophosphamide-dexamethasone; VGPR, very good partial response; VMP, bortezomibmelphalan-prednisone; VRd, bortezomib-lenalidomide-dexamethasone. 
Table 1

Cytogenetic categories of multiple myeloma

\begin{tabular}{|llll|}
\hline Cytogenetic type & Approximate frequency $(\%)$ & Cytogenetic abnormality & Gene(s)/chromosomes affected \\
\hline Hyperdiploid MM & 45 & Hyperdiploid & $\begin{array}{l}\text { Recurrent trisomies involving odd-numbered } \\
\text { chromosomes with the exception of } \\
\text { chromosomes 1, 13, and 21 }\end{array}$ \\
\hline $\mathrm{t}(11 ; 14) \mathrm{MM}$ & 25 & $\mathrm{t}(11 ; 14)(\mathrm{q} 13 ; \mathrm{q} 32)$ & CCND1 (cyclin D1) \\
\hline $\mathrm{t}(4 ; 14) \mathrm{MM}$ & 15 & $\mathrm{t}(4 ; 14)(\mathrm{p} 16 ; \mathrm{q} 32)$ & FGFR3 and $M M S E T$ \\
\hline $\mathrm{t}(14 ; 16) \mathrm{MM}$ & 5 & $\mathrm{t}(14 ; 16)(\mathrm{q} 32 ; \mathrm{q} 23)$ & $C-M A F$ \\
\hline $\mathrm{t}(6 ; 14) \mathrm{MM}$ & 3 & $\mathrm{t}(6 ; 14)(\mathrm{p} 21 ; \mathrm{q} 32)$ & $C C N D 3$ (cyclin $\mathrm{D} 3)$ \\
\hline $\mathrm{t}(14 ; 20) \mathrm{MM}$ & 2 & $\mathrm{t}(14 ; 20)(\mathrm{q} 32 ; \mathrm{q} 11)$ & MAFB \\
\hline Unclassified MM & 5 & $\begin{array}{l}\text { Other abnormalities including rare } \\
14 \mathrm{q} 32 \text { translocations, and } \\
\text { translocations involving } \\
\text { immunoglobulin light chain loci }\end{array}$ & $\mathrm{NA}$ \\
& & & \\
\hline
\end{tabular}

All of the specific translocations listed involve the immunoglobulin heavy chain locus on chromosome 14q32 and the genes listed are located on the respective partner chromosome. Abbreviation: MM, multiple myeloma; NA, not applicable. 
Table 2

Risk stratification of multiple myeloma

\begin{tabular}{|lll|}
\hline Category & Risk factors & Approximate frequency (\%) \\
\hline Low-risk multiple myeloma & Absence of intermediate-risk or high-risk factors & 75 \\
\hline Intermediate-risk multiple myeloma & $\begin{array}{l}\mathrm{t}(4 ; 14) \text { plus absence of 17p deletion or high-risk gene-expression- } \\
\text { profiling signature }\end{array}$ & 10 \\
\hline High-risk multiple myeloma & $\begin{array}{l}\text { Presence of 17p deletion or high-risk gene-expression-profiling } \\
\text { signature }\end{array}$ & 15 \\
\hline
\end{tabular}


Table 3

Common front-line treatment regimens in multiple myeloma

\begin{tabular}{|c|c|c|c|}
\hline Regimen & Suggested starting doses* & $\begin{array}{l}\text { Overall } \\
\text { response } \\
\text { rate }(\%)\end{array}$ & $\begin{array}{l}\text { Estimated } \\
\text { CR }+ \\
\text { VGPR rate } \\
(\%)\end{array}$ \\
\hline Thalidomide-dexamethasone (TD) $)^{31,32}$ & $\begin{array}{l}\text { Thalidomide } 200 \mathrm{mg} \text { oral days } 1-28 \text {; dexamethasone } \\
40 \mathrm{mg} \text { oral days } 1,8,15,22 \text {; repeated every } 4 \text { weeks }\end{array}$ & 65 & 30 \\
\hline Lenalidomide-dexamethasone $(\mathrm{Rd})^{14}$ & $\begin{array}{l}\text { Lenalidomide } 25 \mathrm{mg} \text { oral days } 1-21 \text { every } 28 \text { days; } \\
\text { dexamethasone } 40 \mathrm{mg} \text { oral days } 1,8,15,22 \text { every } 28 \\
\text { days; repeated every } 4 \text { weeks }\end{array}$ & 70 & 40 \\
\hline Bortezomib-dexamethasone (VD) ${ }^{40}$ & $\begin{array}{l}\text { Bortezomib } 1.3 \mathrm{mg} / \mathrm{m}^{2} \text { intravenous days } 1,8,15,22 \\
\text { dexamethasone } 20 \mathrm{mg} \text { on day of and day after } \\
\text { bortezomib (or } 40 \mathrm{mg} \text { days } 1,8,15,22 \text { ); repeated } \\
\text { every } 4 \text { weeks }\end{array}$ & 80 & 40 \\
\hline Melphalan-prednisone-thalidomide (MPT) ${ }^{60,61}$ & $\begin{array}{l}\text { Melphalan } 0.25 \mathrm{mg} / \mathrm{kg} \text { oral days } 1-4 \text { (use } 0.20 \mathrm{mg} / \\
\mathrm{kg} \text { per day oral days } 1-4 \text { in patients over the age of } \\
75 \text { years); prednisone } 2 \mathrm{mg} / \mathrm{kg} \text { oral days } 1-4 ; \\
\text { thalidomide } 100-200 \mathrm{mg} \text { oral days } 1-28 \text { (use } 100 \\
\text { mg dose in patients }>75 \text { years); repeated every } 6 \\
\text { weeks }\end{array}$ & 70 & 30 \\
\hline Bortezomib-melphalan-prednisone (VMP) ${ }^{43}$ & $\begin{array}{l}\text { Bortezomib } 1.3 \mathrm{mg} / \mathrm{m}^{2} \text { intravenous days } 1,8,15,22 \\
\text { melphalan } 9 \mathrm{mg} / \mathrm{m}^{2} \text { oral days } 1-4 \text {; prednisone } 60 \\
\mathrm{mg} / \mathrm{m}^{2} \text { oral days } 1-4 \text {; repeated every } 35 \text { days }\end{array}$ & 70 & 40 \\
\hline Melphalan-prednisone-lenalidomide (MPR) $)^{71}$ & $\begin{array}{l}\text { Melphalan } 0.18 \mathrm{mg} / \mathrm{kg} \text { oral days } 1-4 ; \text { prednisone } 2 \\
\mathrm{mg} / \mathrm{kg} \text { oral days } 1-4 \text {; lenalidomide } 10 \mathrm{mg} \text { oral days } \\
1-21 \text {; repeated every } 4 \text { weeks }\end{array}$ & 67 & 33 \\
\hline Bortezomib-thalidomide-dexamethasone (VTD) ${ }^{15}$ & $\begin{array}{l}\text { Bortezomib } 1.3 \mathrm{mg} / \mathrm{m}^{2} \text { intravenous days } 1,8,15,22 ; \\
\text { thalidomide } 100-200 \mathrm{mg} \text { oral days } 1-21 ; \\
\text { dexamethasone } 20 \mathrm{mg} \text { on day of or after bortezomib } \\
\text { (or } 40 \mathrm{mg} \text { days } 1,8,15,22 \text {; repeated every } 4 \text { weeks } \\
\times 4 \text { cycles as pre-transplant induction therapy }\end{array}$ & 95 & 60 \\
\hline Bortezomib-cyclophosphamide- dexamethasone (VCD) ${ }^{49}$ & $\begin{array}{l}\text { Cyclophosphamide } 300 \mathrm{mg} / \mathrm{m}^{2} \text { orally on days } 1,8, \\
15 \text { and } 22 ; \text { bortezomib } 1.3 \mathrm{mg} / \mathrm{m}^{2} \text { intravenously on } \\
\text { days } 1,8,15,22 ; \text { dexamethasone } 40 \mathrm{mg} \text { orally on } \\
\text { days on days } 1,8,15,22 ; \text { repeated every } 4 \text { weeks }\end{array}$ & 90 & 70 \\
\hline Bortezomib-lenalidomide-dexamethasone (VRD $)^{47,50}$ & $\begin{array}{l}\text { Bortezomib } 1.3 \mathrm{mg} / \mathrm{m}^{2} \text { intravenous days } 1,8,15 \text {; } \\
\text { lenalidomide } 25 \mathrm{mg} \text { oral days } 1-14 \text {; dexamethasone } \\
20 \mathrm{mg} \text { on day of and day after bortezomib (or } 40 \mathrm{mg} \\
\text { days } 1,8,15,22 \text { ); repeated every } 3 \text { weeks }\end{array}$ & 100 & 70 \\
\hline
\end{tabular}

Doses of dexamethasone and bortezomib reduced from initial trial reports to once weekly schedules. Abbreviations: CR, complete response; VGPR, very good partial response. 


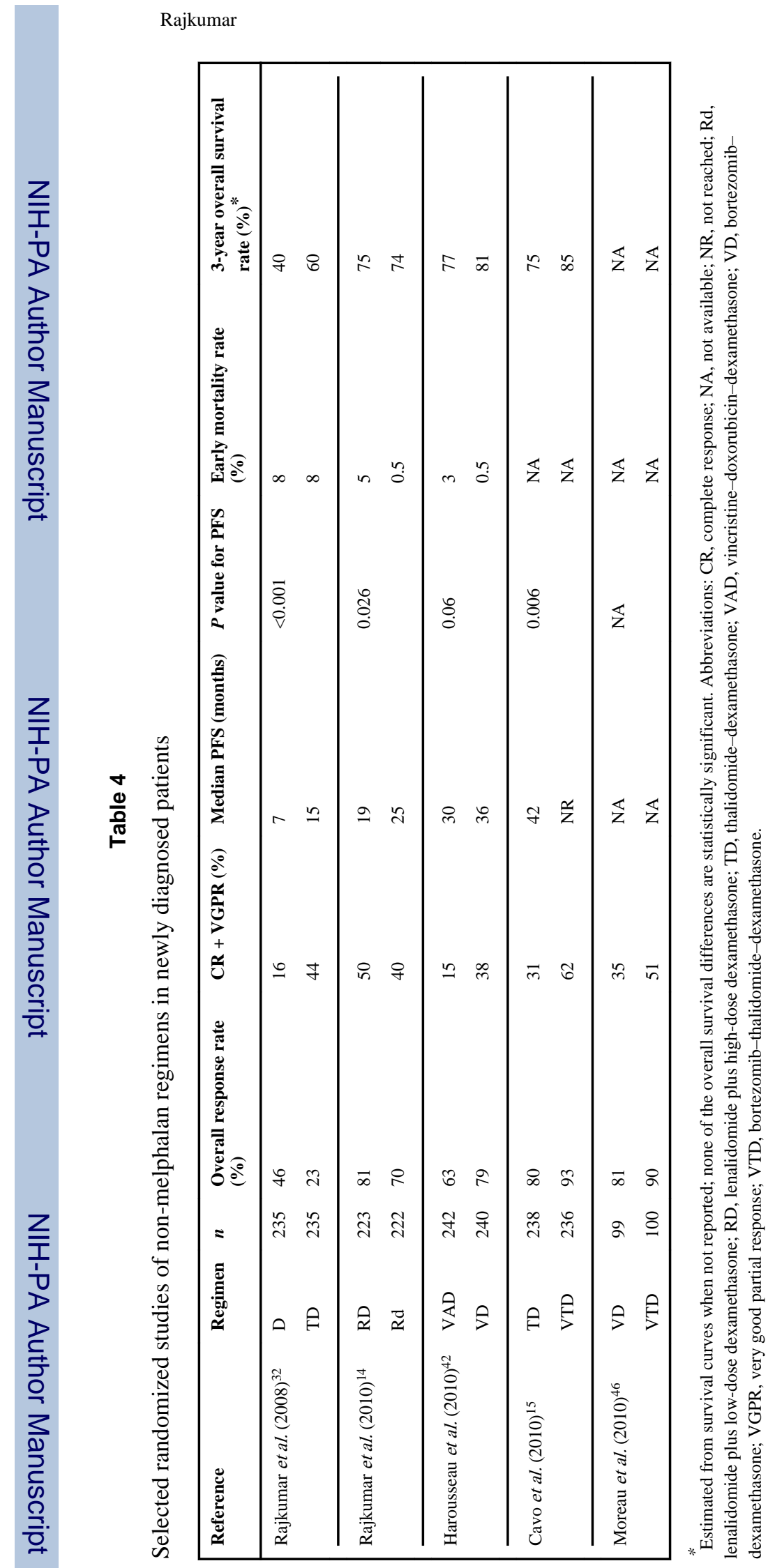

Nat Rev Clin Oncol. Author manuscript; available in PMC 2013 September 15. 


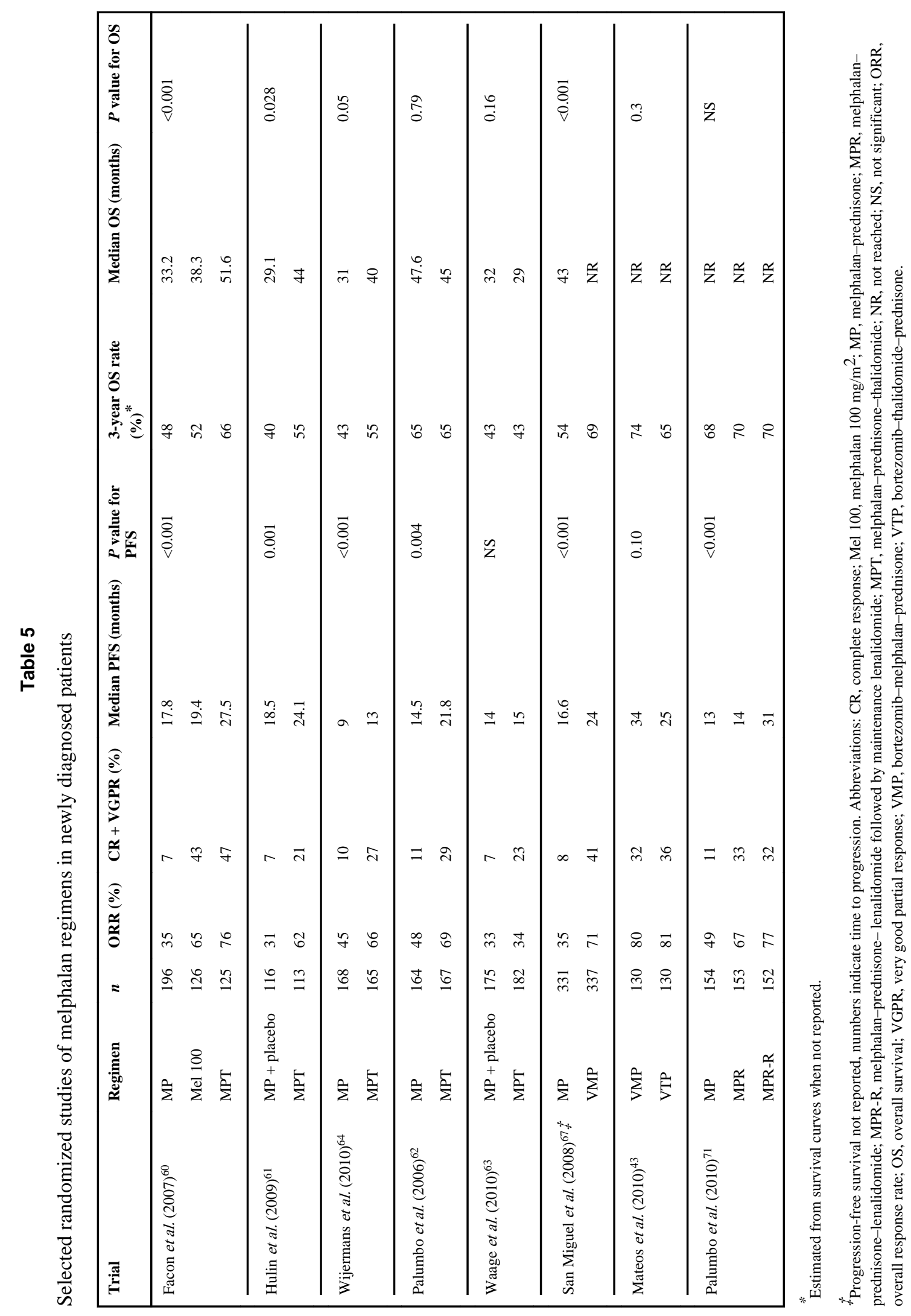


Table 6

Promising novel agents in development for multiple myeloma

\begin{tabular}{|lll|}
\hline Therapeutic target or class of agent & Agent & Comment \\
\hline Immunomodulatory agents & Pomalidomide & Proven single agent activity; in phase III testing \\
\hline Proteasome inhibitors & Carfilzomib MLN9708 & $\begin{array}{l}\text { Proven single agent activity; in phase III testing Oral proteasome } \\
\text { inhibitor in phase I-II trials }\end{array}$ \\
\hline Histone deacetylase inhibitors & $\begin{array}{l}\text { Vorinostat } \\
\text { Panobinostat }\end{array}$ & $\begin{array}{l}\text { Potential clinical activity in combination with bortezomib; in phase III } \\
\text { testing } \\
\text { Potential clinical activity in combination with bortezomib; in phase III } \\
\text { testing }\end{array}$ \\
\hline $\begin{array}{l}\text { Phosphatidylinositol 3-kinase pathway } \\
\text { inhibitors }\end{array}$ & Perifosine & $\begin{array}{l}\text { Inhibitor of Akt activation; potential clinical activity in combination } \\
\text { with bortezomib; in phase III testing }\end{array}$ \\
\hline Anti-CS1 & Elotuzumab & $\begin{array}{l}\text { Monoclonal antibody targeting CS1, a surface glycoprotein expressed } \\
\text { on plasma cells; potential clinical activity in combination with } \\
\text { lenalidomide; in phase III testing }\end{array}$ \\
\hline Heat shock protein 90 inhibitors & Tanespimycin & \begin{tabular}{l} 
Potential clinical activity in combination with bortezomib \\
\hline
\end{tabular}
\end{tabular}


Table 7

Examples of existing clinical paradigms and required paradigm shifts

\begin{tabular}{|c|c|c|}
\hline Current paradigm & Required paradigm shift & Rationale \\
\hline $\begin{array}{l}\text { Treatment is not based on } \\
\text { cytogenetic type or underlying } \\
\text { risk stratification }\end{array}$ & $\begin{array}{l}\text { Targeted therapy based on specific } \\
\text { molecular cytogenetic type and underlying } \\
\text { risk status }\end{array}$ & $\begin{array}{l}\text { The current disease definition is based on a clinical } \\
\text { phenotype; it is clear that myeloma is not a single cytogenetic } \\
\text { disease; the overall survival of some subgroups has not } \\
\text { improved despite the availability of new treatment options, } \\
\text { and specific trials need to be designed for high-risk patients }\end{array}$ \\
\hline $\begin{array}{l}\text { Distinction between clonal } \\
\text { premalignant stage (MGUS) } \\
\text { and clonal malignant stage } \\
\text { multiple myeloma can only be } \\
\text { made by development of } \\
\text { osteolytic bone lesions or } \\
\text { serious end-organ damage }\end{array}$ & $\begin{array}{l}\text { Develop a combination of biomarkers that } \\
\text { can accurately predict patients in whom } \\
\text { malignant transformation has occurred and } \\
\text { enable early therapy before end-organ } \\
\text { damage }\end{array}$ & $\begin{array}{l}\text { In } 2011 \text {, waiting for development of bone lesions, anemia, } \\
\text { and renal failure as the only ways of distinguishing } \\
\text { malignancy from premalignancy must be challenged }\end{array}$ \\
\hline Myeloma is incurable & $\begin{array}{l}\text { Early therapy can potentially cure MM. In } \\
\text { order to do this we need to first develop } \\
\text { reliable methods for discriminating clonal } \\
\text { premalignant stage (MGUS) versus clonal } \\
\text { malignant stage multiple myeloma }\end{array}$ & $\begin{array}{l}\text { Breast cancer, for example, is considered curable only when } \\
\text { treated early. It is not curable in the presence of bone } \\
\text { metastases. Similarly the current paradigm that multiple } \\
\text { myeloma is incurable may be true because we define multiple } \\
\text { myeloma when patients have multiple bone lesions or serious } \\
\text { end-organ damage. Multiple myeloma may be curable if the } \\
\text { disease can be labeled a malignancy and treated early before } \\
\text { development of end-organ damage and multiple lytic bone } \\
\text { lesions }\end{array}$ \\
\hline True CR is the goal of therapy & $\begin{array}{l}\text { Eradication of residual malignant disease is } \\
\text { the goal of therapy. There is no need to } \\
\text { eradicate clonal MGUS premalignant cells, } \\
\text { which are analogous to colon polyps }\end{array}$ & $\begin{array}{l}\text { We need to redefine CR to mean freedom from malignancy- } \\
\text { a state more easily achievable, more realistic, and less toxic. } \\
\text { Currently, true CR (stringent; immunophenotypic; molecular) } \\
\text { means eradication of all traces of clonal plasma cells, which } \\
\text { may be impossible since the residual MGUS like clonal cells } \\
\text { divide exceedingly slowly and resemble normal plasma cells } \\
\text { such that they cannot be eradicated without lethal harm to } \\
\text { patients. In order to do this it is necessary to distinguish } \\
\text { multiple myeloma cells from MGUS cells }\end{array}$ \\
\hline $\begin{array}{l}\text { Treatments need to be } \\
\text { administered at maximum } \\
\text { tolerated doses }\end{array}$ & $\begin{array}{l}\text { Optimal effective dose should be the } \\
\text { standard. Reduced intensity schedule can } \\
\text { improve safety, prolong duration of therapy, } \\
\text { and perhaps improve efficacy }\end{array}$ & $\begin{array}{l}\text { Recent studies testing the dosing of dexamethasone, } \\
\text { thalidomide, bortezomib, and intravenous bisphosphonates } \\
\text { show that more is not always better. Similar or better efficacy } \\
\text { and lower toxicity can be achieved by reduced-intensity } \\
\text { therapy }\end{array}$ \\
\hline
\end{tabular}

Abbreviations: CR, complete response; MGUS, monoclonal gammopathy of undetermined significance. 